\author{
Ruth Schwaninger $\cdot$ Ernst Waelti $\cdot$ Paul Zajac \\ Antoinette Wetterwald · Dominique Mueller \\ Claude D. Gimmi
}

\title{
Virosomes as new carrier system for cancer vaccines
}

Received: 19 December 2003 / Accepted: 22 March 2004/Published online: 5 June 2004

(C) Springer-Verlag 2004

\begin{abstract}
HER-2/neu, a tumor-associated antigen (TAAg), plays a critical role in oncogenesis of various tumor types, and its selective overexpression by malignant tumor cells makes it an ideal target for immunotherapy. A prerequisite for clinical vaccines is the construction of safe and highly immunogenic reagents able to generate efficient immune responses against TAAg. Previous protein vaccines, consisting of the extracellular domain of HER$2 /$ neu ( $p^{\text {NeuECD }}$ ), were shown to elicit an immune response that did not provide protection from transplantable tumors expressing HER-2/neu. Here we showed that virosomes, which consist of reconstituted viral envelopes without viral genetic material, can act as a carrier and an adjuvant for a truncated protein $\mathrm{p}^{\mathrm{NeuECD}}$. Mice vaccinated with $\mathrm{p}^{\text {NeuECD }}$ either encapsulated in virosomes or bound to the virosomal membrane (Vir-p $\left.\mathrm{p}^{\text {NeuECD}}\right)$, generated rNeu-specific humoral and cytotoxic immune responses. In addition, Vir-p ${ }^{\text {NeuECD }}$ induced significant tumor rejection and additionally did not lead to delayed tumor formation when compared with free $p^{\text {NeuECD }}$ in complete Freund's adjuvant. There was no difference between the virosomal constructs. Taken together these results suggest that virosomes, as clinically approved safe vaccines, can be used to elicit both humoral and cell-
\end{abstract}

Ruth Schwaninger and Ernst Waelti contributed equally to this article

R. Schwaninger $\cdot$ C. D. Gimmi

Department of Clinical Research, University of Bern,

Bern, Switzerland

E. Waelti · A. Wetterwald · D. Mueller

Institute of Pathology, University of Bern, Bern, Switzerland

P. Zajac

Research Department, Kantonsspital Basel, Basel, Switzerland

C. D. Gimmi $(\bowtie)$

Global Drug Development, Oncology, F. Hoffmann-LaRoche, PDM2, Grenzacherstrasse, 4070 Basel, Switzerland

E-mail: Claude.Gimmi@Roche.com

Fax: + 41-61-6887744 mediated responses against TAAg and induce tumor rejection. Our model is providing important preclinical data to design human vaccination trials for patients with tumors overexpressing HER-2/neu, either as a primary vaccination or as a boost in combination with other vaccines in a context of an adjuvant treatment plan.

Keywords HER-2/neu oncogene - Tumor rejection · Tumor vaccines $\cdot$ Virosomes

\section{Introduction}

HER-2/neu, a transmembrane tyrosine kinase, has been linked to the malignant transformation of human breast, prostate, lung, and colorectal tumors [1-4]. HER-2/neu has become an attractive target and recognized antigen for immunotherapy, as both detectable HER-2/neu-specific IgG antibodies and cytotoxic T cell (CTL) responses have been demonstrated in patients with cancer overexpressing HER-2/neu, thus indicating that self-tolerance has been circumvented $[5$, 6]. A prerequisite for clinical applications of immunotherapy or cancer vaccines is the construction of highly immunogenic reagents able to efficiently generate immune responses against tumor-associated antigens (TAAgs). Replication incompetent viral vectors, developed to express TAAgs, have been demonstrated to be safe and potent in generating a humoral and cellular immune response [7, 8]. However, despite the superiority of viral vaccines there is an increasing safety concern when oncogenic DNA inserts are involved. In contrast, virosomes represent an attractive new delivery system to antigen-presenting cells (APCs) based on their unique targeting and membrane fusion properties [9]. Virosomes are reconstituted influenza viral envelopes, which lack the genetic material but retain the cell entry and membrane fusion characteristics of the virus they are derived from [10]. By virtue of this membrane fusion activity they can introduce exogenous antigens 
directly into the cytosols of APCs, thus accessing the MHC class I pathway without de novo protein synthesis [11-13]. In addition to facilitating the uptake of exogenous proteins, virosomes have also been shown to act as immunoadjuvants and to induce an efficient humoral and cytotoxic immune response in primed mice against viral antigens [14].

In our study, we used virosomes as an immunoadjuvant and new antigen carrier system to investigate the immune response and tumor rejection capacity of vaccinated mice in comparison to protein and viral vaccines. We chose HER-2/neu as a model tumor antigen and used the extracellular domain of HER-2/neu protein $\left(p^{\text {NeuECD}}\right)$, first to avoid the restriction of immunodominant epitopes and second to generate durable immunity by immunizing with putative T-helper epitopes. Our results showed that virosomes could be used as carrier and immunoadjuvant for a truncated $\mathrm{p}^{\mathrm{NeuECD}}$ protein encapsulated or bound to different virosomal constructs (Vir-p ${ }^{\text {NeuECD }}$ ). Vir-p ${ }^{\text {NeuECD }}$ protected a significant number of mice from tumor formation compared with free $\mathrm{p}^{\text {NeuECD }}+$ complete Freund's adjuvant (CFA) and this protection correlated with the induction of cytotoxic and humoral immune responses. This paper supports the use of virosomes as a new and safe carrier system and adjuvant for cancer vaccines.

\section{Material and methods}

\section{Chemicals}

$N$-Hydroxysuccinimide ester of palmitic acid (NHSP), $N$-(1-(2,3-dioleyloxy)propyl)- $N, N, N$-trimethylammonium methyl sulfate (DOTAP), and 3-sn-phosphatidylcholine (PC; Sigma, St Louis, MO, USA).

Mice

Female virgin MMTV/r-Neu FVB mice (H-2q) transgenic for the rat neu protein (rNeu-TG) and FVB/N mice $(\mathrm{H} 2 \mathrm{q})$ were purchased from Charles River, Germany. Laboratory animal care was in accordance with institutional guidelines.

\section{Cell lines}

IT22 3T3 (H-2q) fibroblasts were cotransfected with a SV2-Neo-SP65 and a pBR322-rNeu plasmid. G418-resistent $\mathrm{rNeu}^{+}$clones (IT22-neu) were selected for their rNeu expression by indirect immunofluorescence by FACS. The syngeneic $\mathrm{rNeu}^{+}(\mathrm{H}-2 \mathrm{q})$ breast cancer cell line NF9006 derived from a rNeu-TG mouse and the syngeneic $\mathrm{rNeu}^{-}(\mathrm{H}-2 \mathrm{q})$ breast cancer cell line $\mathrm{K} 635$ derived from a c-myc-TG mouse have previously been described [15].
Amplification and cloning of the extracellular part of HER-2/neu ( $\left.\mathrm{Neu}_{\mathrm{ECD}}\right)$

The DNA sequence coding for the extracellular part of rat HER-2/neu (corresponding to amino acid 1-655) was amplified by PCR. The following primers were used: 5'-AATTCGCAATGATCATCATGGAGCTG-3' $\left(5^{\prime}\right.$ primer) and 5'-GCCAGCCCGGTGACATAA-3' ( $3^{\prime}$ primer) using pSV2neuN [16] as template. The $3^{\prime}$ primer contained a stop codon, so that only the extracellular part of HER-2/neu was expressed. The fragment was cloned into pVAX1 (Invitrogen, Cat: V260-20; Groningen, Netherland), amplified, purified, and used as a vaccine, either as free DNA or packed into virosomes.

\section{Immunohistochemistry}

Cytospins of NF9006 and Vir-DNA-Neu $\mathrm{ECD}_{\text {infected }}$ COS cells were incubated with a mouse anti-rat HER-2/ neu (7.16.4, Oncogene Science) Ab diluted in PBS and goat serum. After incubation with biotin-conjugated goat antimouse Ab (Dako, Copenhagen, Denmark), reactivities were detected using an avidin-biotin complex (Dako) and Newfuchsin substrate (Sigma) according to manufacturer's instructions.

Expression plasmid construction, protein expression, and isolation/purification of the $\mathrm{p}^{\mathrm{NeuECD}}$

cDNA encoding the extracellular part of rat Neu $\left(\mathrm{Neu}_{\mathrm{ECD}}\right)$ was ligated into MCS of the pBADHisB expression vector (Invitrogen). For protein expression pBADHisB-Neu $\mathrm{ECD}_{\mathrm{E}}$ was grown in Escherichia coli to an $\mathrm{OD}_{600}$ of 0.5 , protein expression was induced with L-arabinose at a final concentration of $0.2 \%$ for $3 \mathrm{~h}$. Cells were then pelleted and sonicated, and $\mathrm{p}^{\text {NeuECD }}$ was isolated and purified from the collected lysates by quantitative SDS PAGE with Model 491 Prep Cell (BioRad Laboratories, Glattbrugg, Switzerland) according to the manufacturer's instructions. Purified fractions were collected and analyzed in a Western blot.

\section{Fatty acylation of the $\mathrm{p}^{\mathrm{NeuECD}}$}

To attach the antigen $\left(\mathrm{p}^{\mathrm{NeuECD}}\right)$ to the surface of the virosomal lipid bilayer, $\mathrm{p}^{\mathrm{NeuECD}}$ was covalently coupled to palmitic acid using a fatty acylation reaction [17].

Preparation of DNA plasmid-virosome complexes (Vir-DNA-Neu $\left.{ }_{E C D}\right)$

Plasmid pVAX1-Neu $\mathrm{ECD}_{\mathrm{E}}$ was encapsulated in virosomes as follows. A $1.5-\mathrm{ml}$ solution of plasmid $(590 \mu \mathrm{g})$ was added to $3 \mathrm{ml}$ of HBS (Hepes, $20 \mathrm{mmol} / \mathrm{l} ; \mathrm{NaCl}$, $150 \mathrm{mmol} / \mathrm{l}, \mathrm{pH} \mathrm{7.4)}$ and mixed with $1.5 \mathrm{ml}$ of HBS 
containing 2.95-mg DOTAP and then ultrasonicated. Furthermore, influenza virosomes containing 70\% DOTAP in the lipid membrane were prepared as described previously [18]. DNA plasmid-virosome complexes were prepared by mixing DOTAP-encapsulated plasmid liposomes $(6 \mathrm{ml})$ with $2.8 \mathrm{ml}$ of DOTAP-virosomes, and subsequently fused by ultrasonication at room temperature. The resulting solution contained $66.2 \mu \mathrm{g}$ plasmid $/ \mathrm{ml}$.

Preparation of Vir-p ${ }^{\text {NeuECD }}$ mem

Hemagglutinin (HA) from the A/Singapore/6/86 strain of influenza virus was isolated as previously described $[18,19]$. Supernatant containing solubilized HA trimer $(3.9 \mathrm{mg} / \mathrm{ml})$ in $0.01 \mathrm{M} \mathrm{E}_{12} \mathrm{E}_{8}$ was used for the production of virosomes. PC $(112 \mathrm{mg})$ in chloroform was added to a round-bottomed flask, and the chloroform was evaporated by a rotary evaporator. The supernatant ( $7.1 \mathrm{ml}$ containing $28 \mathrm{mg} \mathrm{HA}$ ) and $11 \mathrm{ml}$ of palmitoyl $\mathrm{p}^{\text {NeuECD }}$ were added to the flask. The PC film was solubilized under gentle shaking. The mixture was briefly treated by ultrasonication and then filtered through a $0.2-\mu \mathrm{m}$ filter. The detergent of the resulting solution was removed by extraction with sterile Biobeads SM-2 (BioRad, Richmond, CA, USA). The content of palmitoyl $\mathrm{p}^{\text {NeuECD }}$ was verified by Western blot (see below).

Preparation of Vir-p ${ }^{\mathrm{NeuECD}}$ enc

Vir-p ${ }^{\text {NeuECD }}$ enc was prepared as described above with the exception that the antigen $p^{\text {NeuECD }}$ was added to the mixture. After formation of virosomes, nonencapsulated material was removed by size exclusion chromatography on a High Load Superdex 200 column (Pharmacia, Uppsala, Sweden). The content of $\mathrm{p}^{\mathrm{NeuECD}}$ was determined by Western blot as mentioned below.

Western blot analysis

The $\mathrm{p}^{\text {NeuECD }}$ in the different preparations was identified using anti-6xHis monoclonal antibody (Clontech Laboratories, Palo Alto, CA, USA) and sheep antimouse AP-conjugated Ig (Chemicon, Temecula, CA, USA) as secondary antibody. Content of $\mathrm{p}^{\mathrm{NeuECD}}$ was estimated using QuantiScan (Biosoft, Cambridge, UK).

Generation and inactivation of recombinant vaccinia virus vector, $\mathrm{rVV}-\mathrm{Neu}_{\mathrm{ECD}}$

The domain of $\mathrm{Neu}_{\mathrm{ECD}}$ was first cloned into a vaccinia shuttle vector (generous gift from Dr K.Tsung, San Francisco, CA, USA) enabling insertion and transcription in the viral genome. The insert was flanked by two viral sequences enabling homologous recombination in the A56R loci (hemagglutinin-nonessential gene) of vaccinia virus (Copenhagen strain). A clonal recombinant virus was obtained after several rounds of plaque isolation (using transient gpt selection [20]) on CV-1 cells (ATCC CCL70). Several separately isolated clones were PCR screened and one positive recombinant was then amplified and concentrated on $36 \%$ sucrose cushions. Viral solutions were titered on CV-1 cells. Virus replication was inactivated by a limited treatment with $1 \mu \mathrm{g} / \mathrm{ml}$ psoralen (Trioxsalen; Calbiochem, Cambridge, MA, USA) for $10 \mathrm{~min}$ at room temperature followed by $8 \mathrm{~min}$ exposure to 354-nm long-wave UV (Stratalinker; Stratagene, La Jolla, CA, USA) as described previously $[8,21]$.

FACS analysis for Neu expression on cell line and rNeu-specific antibody levels in serum

Syngeneic fibroblast cells (IT22-neu) were analyzed for their rNeu-expression as previously described [22]. $\mathrm{RNeu}^{+} \mathrm{NF9006}$ cells $\left(0.5 \times 10^{6}\right)$ were used to determine rNeu-specific antibodies in sera of mice after different vaccines. The method used and cell analysis for fluorescence on a FACScan has been previously described [23].

\section{Vaccination protocols}

Vaccination/boost studies were performed in female virgin FVB mice as previously described [15] with the following vaccines: $1 \times 10^{8} \mathrm{pfu}$ recombinant vaccinia virus (rVV) encoding for $\mathrm{Neu}_{\mathrm{ECD}}\left(\mathrm{rVV}-\mathrm{Neu}_{\mathrm{ECD}}\right)$ i.p., or $1 \times 10^{8}$ pfu wild type vaccinia virus (WT-VV) i.p., or $20 \mu \mathrm{g}$ of plasmid DNA pVAX1 (fDNA) i.m. or s.c., or $20 \mu \mathrm{g}$ of pVAX1 encoding for $\mathrm{Neu}_{\mathrm{ECD}}$ (fDNA$\mathrm{Neu}_{\mathrm{ECD}}$ ) i.m. or s.c., or $20 \mu \mathrm{g}$ of fDNA-Neu encapsulated in virosomes (Vir-DNA-Neu $\mathrm{ECD}_{\mathrm{E}}$ ) i.p. In other sets of experiments the following vaccines were used: $20 \mu \mathrm{g}$ of free $\mathrm{p}^{\mathrm{NeuECD}}$ with $50 \mu \mathrm{l}$ of CFA adjuvant $(N$-acetylglycosaminyl- $(\beta 1-4)-N$-acetylmuramylL-alanyl-D- isoglutamine; Gerbu, Gaiberg, Germany) s.c., or $20 \mu \mathrm{g}$ of $\mathrm{p}^{\mathrm{NeuECD}}$ encapsulated in virosomes (Vir$\mathrm{p}^{\text {NeuECD }}$ enc), or $20 \mu \mathrm{g}$ of $\mathrm{p}^{\text {NeuECD }}$ bound to virosome membranes (Vir-p NeuECD mem), or a mixture of the two (Vir-p ${ }^{\text {NeuECD }}$ enc/mem), or empty virosomes all injected i.p. Two weeks after boost, mice were challenged in the back by a subcutaneous (s.c.) injection of $0.5 \times 10^{6} \mathrm{rNeu}^{+}$ tumor cells. Tumor formation and size was assessed every 3 days using a calibrator. The tumor progression was monitored at the challenge site for 8 weeks.

\section{CTL generation}

Spleen cells (at $5 \times 10^{5}$ cells/well) were restimulated in vitro on irradiated IT22-neu cells seeded at $1.5 \times 10^{5}$ cells/ well in 24-well plates. Spleen cells were cocultured for 
5 days, then used for the cytotoxicity assay described below.

\section{XTT-based cytotoxicity assay}

Lytic function of restimulated effector cells against IT22neu and IT22 target cells was evaluated at different effector to target ratios $(\mathrm{E} / \mathrm{T} 100: 1-0.3: 1)$ in triplicate samples. After overnight coincubation of effector and target cells, $50 \mu \mathrm{l}$ of XTT-solution (Roche Diagnostics, Rotkreuz, Switzerland) was added to each well according to the manufacturer's instructions, and absorbance at $490 \mathrm{~nm}$ was evaluated on an ELISA reader (BioRad). Percentage specific lysis was calculated for each E/ $\mathrm{T}$ ratio as follows: stimulatory cytidine-phosphate-guanosine motifs for increased activation of $\mathrm{B}$ cells, T cells, and dendritic cells [24]. We engineered a fDNA-Neu $\mathrm{ECD}_{\mathrm{E}}$ plasmid designed to express the extracellular domain of rat $\mathrm{Neu}\left(\mathrm{Neu}_{\mathrm{ECD}}\right)$. Before testing this plasmid as vaccine in vivo, the protein expression in transfected COS cells was evaluated in immunohistochemical analysis. Cells transfected with fDNA-Neu $\mathrm{ECD}_{\mathrm{EC}}$ stained strongly when a mouse antibody (Ab) recognizing an extracellular epitope of $\mathrm{rNeu}(\mathrm{Ab}$ 7.16.4) was used, whereas no expression could be detected in the same cells when a rabbit antibody recognizing an epitope of the intracytoplasmic part of human/ rat Neu was selected (data not shown). To confirm $\mathrm{rNeu}_{\mathrm{ECD}}$ protein production in cells transfected with plasmid DNA-Neu $\mathrm{ECD}_{\mathrm{E}}$ encapsulated in virosomes (VirDNA-Neu $\mathrm{ECD}_{\mathrm{E}}$ ), immunohistochemical staining was

$\%$ lysis $=\frac{\text { OD }(\text { target alone })-\text { OD }[(\text { target }+ \text { effectors })-(\text { effectors alone })]}{\text { OD }(\text { target alone })}$

$\%$ Neu-specific killing

$=\%$ killing of specific targets (IT22-neu)

- \%killing of unspecific targets (IT22)

ELISA analysis of anti-p ${ }^{\text {NeuECD }}$

Anti- $p^{\text {NeuECD }}$ specific antibodies in the sera of mice were determined by an ELISA in flat-bottomed plates coated with $\mathrm{p}^{\mathrm{NeuECD}}$ in 50-mM carbonate buffer $(\mathrm{pH} 8.5)$ overnight. Serum samples were diluted in sample buffer 1:25. As a detecting antibody, horseradish peroxidaselabeled sheep antimouse Ig (Amersham Pharmacia Biotech, UK) was used at a dilution of 1:1,000. The reaction was developed by tetramethylbenzidine (TMB) substrate solution and stopped by the addition of $1-\mathrm{m}$ $\mathrm{H}_{2} \mathrm{SO}_{4}$.

\section{Statistical analysis}

All statistical analyses were made using the MannWhitney rank test. For all cases, results were considered significant if $p$ values were $<0.05$.

\section{Results}

RNeu protein is expressed in cells transfected with plasmid encapsulated virosomes

To evaluate whether plasmid DNA (fDNA) encapsulated in virosomes would result in expression of the cloned gene and induce protein production, we chose a plasmid vector containing a strong promoter (CMV) for optimal expression in mammalian cells and immuno- performed on cytospins of Vir-DNA-Neu $\mathrm{ECD}_{\mathrm{E}}$ infected COS cells using again the mouse monoclonal antibody 7.16.4 against rat $\mathrm{Neu}_{\mathrm{ECD}}$ (Fig. 1). The spontaneous breast tumor cell line NF9006, as control, showed a strong staining with mAb 7.16.4 (Fig. 1a). COS cells transfected with Vir-DNA-Neu $\mathrm{ECD}_{\mathrm{E}}$ showed a clear staining for $\mathrm{Neu}_{\mathrm{ECD}}$ protein in the cytoplasm of $20-30 \%$ of these cells using the same mAb 7.16.4 (Fig. 1b). No staining could be detected in COS cells transfected with empty virosomes or Vir-DNA (no insert) when the same antibody was used (Fig. 1c, d). These results confirmed that cells transfected with plasmid DNA-Neu encapsulated in virosomes were capable of producing the antigen.

Prophylactic vaccination with fDNA-Neu $\mathrm{ECD}_{\mathrm{E}}$ significantly inhibits tumor formation

Virosomes have been used as carriers for the introduction of nucleic acid into mammalian cells in vitro [18]. To evaluate whether Vir-DNA-Neu $\mathrm{ECD}_{\mathrm{E}}$ could be used as vaccine and increase rejection of a tumor challenge compared with fDNA-Neu $\mathrm{ECD}_{\mathrm{E}}$, the following experiments were performed: MMTV/r-Neu and/or FVB/N female mice were vaccinated and boosted with recombinant vaccinia virus encoding $\mathrm{Neu}_{\mathrm{ECD}}$ (rVV$\mathrm{Neu}_{\mathrm{ECD}}$ ), with wild-type vaccinia (WT-VV) as negative control, with fDNA (no insert), with fDNA-Neu $\mathrm{ECD}_{\mathrm{E}}$, or with Vir-DNA-Neu $u_{E C D}$ (as described in "Material and methods"). Two weeks after the boost, mice were challenged with either the syngeneic $\mathrm{rNeu}^{+}$(NF9006) or $\mathrm{rNeu}^{-}$(K635) breast cancer cell lines and assessed for tumor formation at the challenge site. As shown in Table 1, immunization with fDNA-Neu $\mathrm{ECD}_{\mathrm{E}}$ s.c. protected 11 out of 15 mice from tumor formation (tumor incidence $4 / 15$ ). The specificity of this protection was

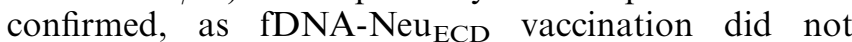




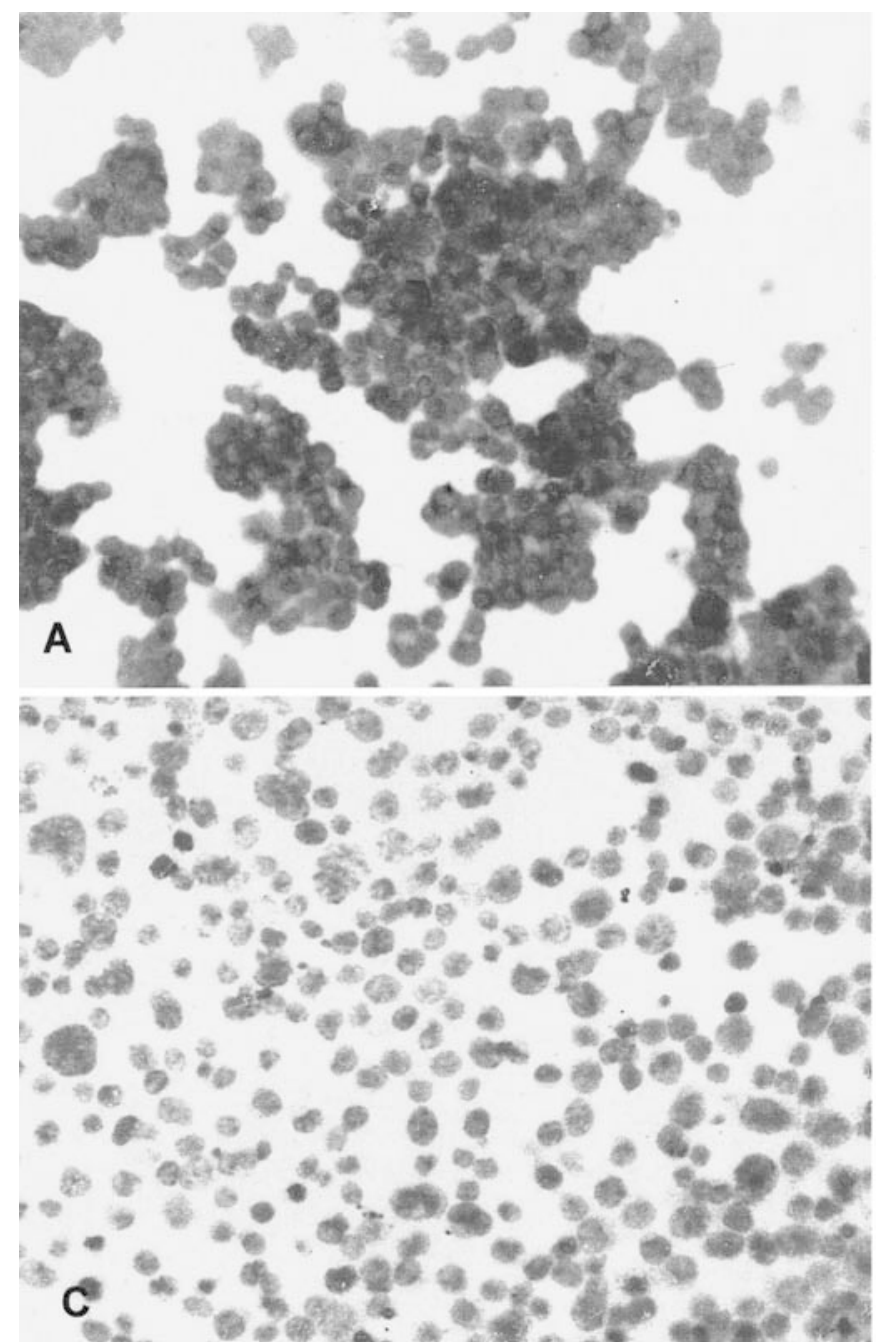

Fig. 1a-d Expression of $\mathrm{rNeu}_{\mathrm{ECD}}$ on a breast cancer cell line and transfected COS cells. a Neu ${ }^{+}$breast cancer cell line (NF9006); b COS cells transfected with Vir-DNA-Neu $\mathrm{ECD}_{2}$ c COS cells transfected with empty Vir; d COS transfected with Vir-DNA. (Magnification a, c, and $\mathbf{d}: \times 280$, and $\mathbf{b}: \times 560$ ). Bar is $50 \mu \mathrm{m}$

protect mice from forming tumors after a challenge with the $\mathrm{rNeu}^{-}$syngeneic breast cancer cell line (K635). In contrast, the immunization with Vir-DNA-Neu $\mathrm{ECD}_{\mathrm{C}}$ resulted in a lack of protection, as 13 mice out of 14

Table 1 Vaccination with fDNA but not with Vir-DNA partially prevents tumor formation. Mice were vaccinated and boosted with WT-VV i.p., rVV-Neu $\mathrm{ECD}_{\text {i.p., fDNA s.c., fDNA-Neu }}$ ECD s.c., VirDNA-Neu ${ }_{E C D}$ i.p. Two weeks after the boost, each group was

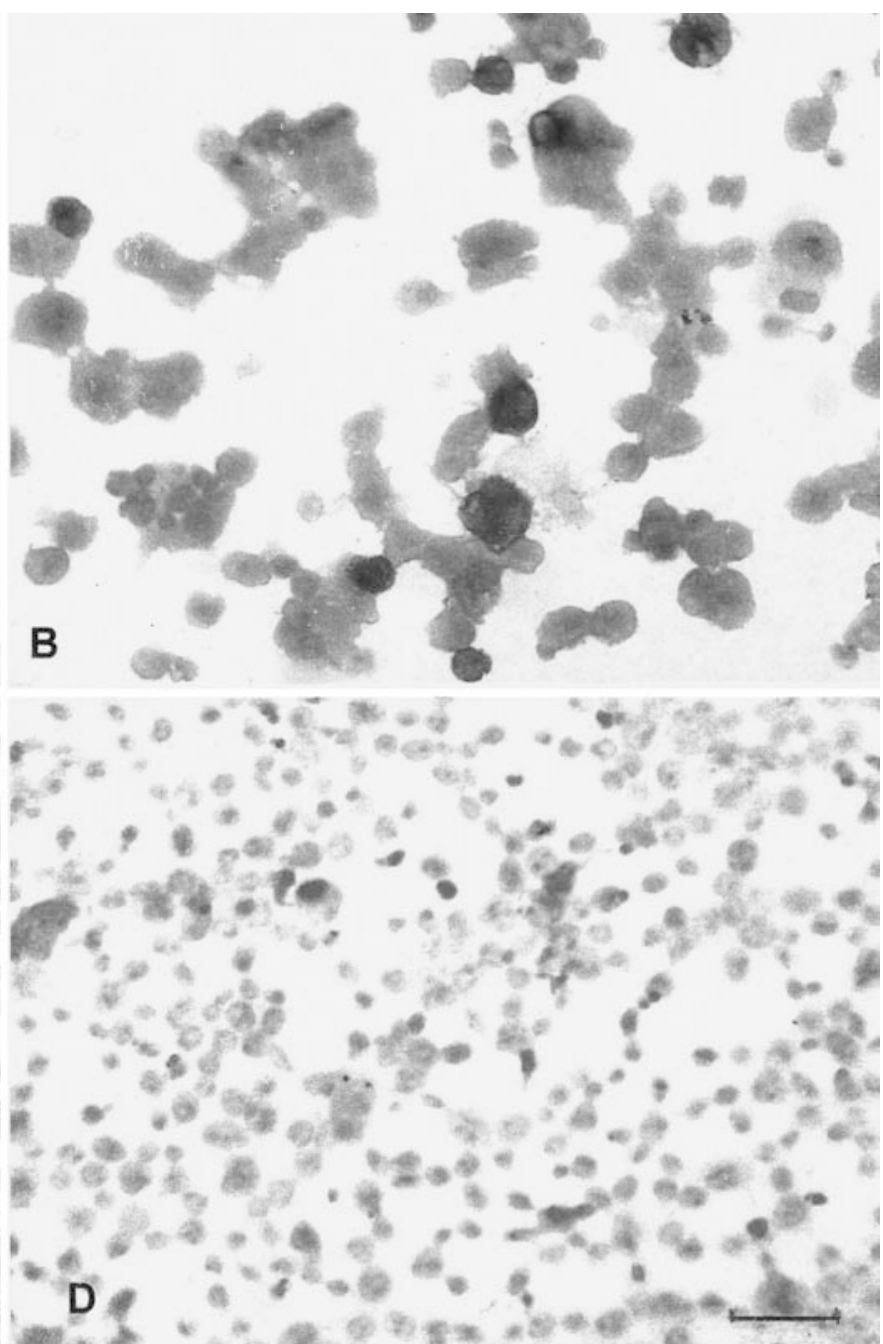

developed tumors with NF9006 breast cancer cells. The injection of Vir-DNA-Neu $\mathrm{ECD}_{\mathrm{E}}$ s.c. or i.p. showed no difference in tumor rejection. None of the $r V V-N e u_{E C D}$ vaccinated mice developed tumors for an observation period more than 2 months, whereas all mice vaccinated with WT-VV and fDNA (no insert), developed tumors at the challenge site. These results indicated that Vir-

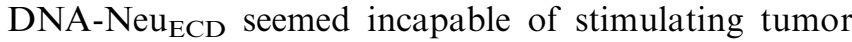
rejection.

challenged s.c. with either $0.5 \times 10^{6} \mathrm{Neu}^{+}$tumor cells (NF9006) or $0.5 \times 10^{6} \mathrm{Neu}^{-}$tumor cells (K635), and tumor progression was monitored at the challenge site for 8 weeks. The results combine four independent experiments

\begin{tabular}{|c|c|c|c|c|}
\hline \multirow[t]{2}{*}{ Vaccination } & \multicolumn{4}{|l|}{ Tumor incidence } \\
\hline & ${\text { With } \mathrm{rNeu}^{+} \text {challenge }}$ & & With $\mathrm{rNeu}^{-}$challenge & \\
\hline rVV-Neu ${ }_{E C D}$ & $0 / 13$ & $(0 \%)$ & $5 / 7$ & $(71 \%)$ \\
\hline WT-VV & $9 / 9$ & $(100 \%)$ & $6 / 6$ & $(100 \%)$ \\
\hline fDNA-Neu $\mathrm{ECD}_{\mathrm{E}}$ & $4 / 15$ & $(26 \%)$ & $5 / 5$ & $(100 \%)$ \\
\hline fDNA & $11 / 11$ & $(100 \%)$ & $3 / 3$ & $(100 \%)$ \\
\hline Vir-DNA-Neu ${ }_{E C D}$ & $13 / 14$ & $(92 \%)$ & n.d. & \\
\hline
\end{tabular}


FDNA-Neu $u_{\mathrm{ECD}}$, but not Vir-DNA-Neu $\mathrm{ECD}_{\mathrm{E}}$, generates rNeu-specific cytotoxic and humoral immune responses

We then examined whether mice vaccinated with fDNA$\mathrm{Neu}_{E C D}$, either free or encapsulated in virosomes (Vir-

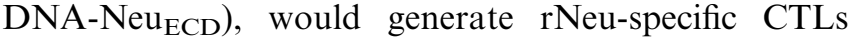
and/or anti-rNeu Ab responses. A syngeneic rNeu-positive IT22 fibroblast cell line was used as target cells in CTL experiments (see "Material and methods"). IT22neu expressed significant amounts of cell surface rNeu as monitored by immunofluorescence staining (Fig. 2). No rNeu expression was detected on IT22 fibroblasts. Also shown in Fig. 2 is the MHC class I and MHC class II staining of the two syngeneic fibroblast cell lines. Both cell lines expressed similar levels of MHC class I and were negative for MHC class II.

Having demonstrated that vaccination and boost induced tumor rejection in fDNA-Neu $\mathrm{ECD}_{\mathrm{E}}$ but not in VirDNA-Neu ${ }_{E C D}$ vaccinated mice, rNeu-specific CTLs were analyzed in spleen cells of animals vaccinated either with fDNA-Neu $u_{E C D}$, Vir-DNA-Neu $u_{E C D}$, fDNA (no insert), rVV-Neu $u_{E C D}$, or WT-VV, using a colorimetric assay with XTT. As shown in Fig. 3a, the CTL activity was most effective in mice immunized with $\mathrm{rVV}-\mathrm{Neu}_{\mathrm{ECD}}$, with a 613-fold greater rNeu-specific lytic activity compared with mice vaccinated with WT-VV. Spleen cells from mice

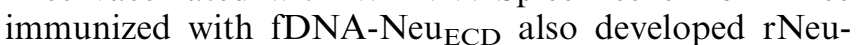
specific killing in vitro at different effector to target ratios; however, at a reduced percentage level as mice vaccinated with $\mathrm{rVV}-\mathrm{Neu}_{\mathrm{ECD}}$. In contrast, there were only background levels of specific cell lysis in mice vaccinated with Vir-DNA-Neu $u_{E C D}$, similar to mice vaccinated with fDNA (no insert) and WT-VV.

To determine whether immunization with the abovementioned vaccines would induce a rNeu-specific humoral immune response, sera of vaccinated and boosted mice were collected at days 49-56 after the first vaccination. The presence of anti-rNeu antibodies was assessed by flow cytometry as previously described [23]. As shown in Fig. 3b, sera from mice injected with rVV$\mathrm{Neu}_{\mathrm{ECD}}$ showed an impressive level of antibody binding $($ mean $=31.8, \mathrm{SEM}=8.9)$. Similarly, an increase of antibody binding over baseline was noticed in fDNA$\mathrm{Neu}_{\mathrm{ECD}}$ vaccinated mice (mean $\left.=22.3, \mathrm{SEM}=11.0\right)$. In comparison, mice primed with Vir-DNA-Neu $\mathrm{ECD}_{\mathrm{E}}$ produced no rNeu-specific IgG (mean $=16.3$, SEM $=5.0$ ) similar to sera from mice immunized with fDNA or WT$\mathrm{VV}$ (both mean $=15.8, \mathrm{SEM}=4.2$ ).

Taken together, these results indicated that the difference in tumor rejection between fDNA-Neu $\mathrm{ECD}_{\mathrm{E}}$ and Vir-DNA-Neu $\mathrm{ECD}_{\mathrm{E}}$ correlated with the discrepancy of the induced cellular and humoral immune responses by the two vaccines.

Virosomes can act as protein carrier system and significantly increase tumor rejection compared with free protein

To investigate whether virosomes could be used as carrier and adjuvant for protein $\mathrm{TAAg}$, we produced $\mathrm{Neu}_{\mathrm{ECD}}$-protein $\left(\mathrm{p}^{\mathrm{NeuECD}}\right)$, using a truncated $\mathrm{rNeu}_{\mathrm{ECD}}$ protein of $90 \mathrm{kDa}$ and engineered two different virosomal constructs; in the first construct, $p^{\text {NeuECD }}$ was encapsulated into the lumen of virosomes (Vir$p^{\text {NeuECD }}$ enc), whereas in the second construct, $p^{\text {NeuECD }}$ was inserted into the lipid bilayer by covalently coupling $\mathrm{p}^{\text {NeuECD }}$ to the palmitoyl fatty acid residues (Vir-p ${ }^{\text {NeuECD }}$ mem). In a Western blot analysis the different virosomal constructs demonstrated approximately the same amount of $\mathrm{p}^{\mathrm{NeuECD}}$ (data not shown).

We investigated whether vaccination with these virosomal constructs (Vir-p ${ }^{\text {NeuECD }}$ enc, Vir-p $p^{\text {NeuECD }}$ mem, or the combination of both Vir- $\mathrm{p}^{\mathrm{NeuECD}} \mathrm{mem} /$
Fig. 2 FACs analysis of rNeutransfected syngeneic IT22 fibroblast cell lines: IT22 were cotransfected with a control neomycin vector and with a vector expressing rNeu (IT22neu). IT22 and IT22-neu cell lines were analyzed for HER-2/ neu cell surface expression by indirect immunostaining using the rNeu-specific mAb (7.16.4) followed by RPE-conjugated goat antimouse IgG. For analysis of MHC class I expression, the biotin antimouse $\mathrm{H}-2 \mathrm{D}^{\mathrm{q}} / \mathrm{H} 2 \mathrm{~L}^{\mathrm{q}}$ (KH117) and for MHC class II the biotin antimouse $\mathrm{I}-\mathrm{A}^{\mathrm{q}}$ (KH116) were used, followed by streptavidin-RPE. The dark shaded area indicates control staining with RPE-conjugated goat antimouse IgG or streptavidin-RPE alone
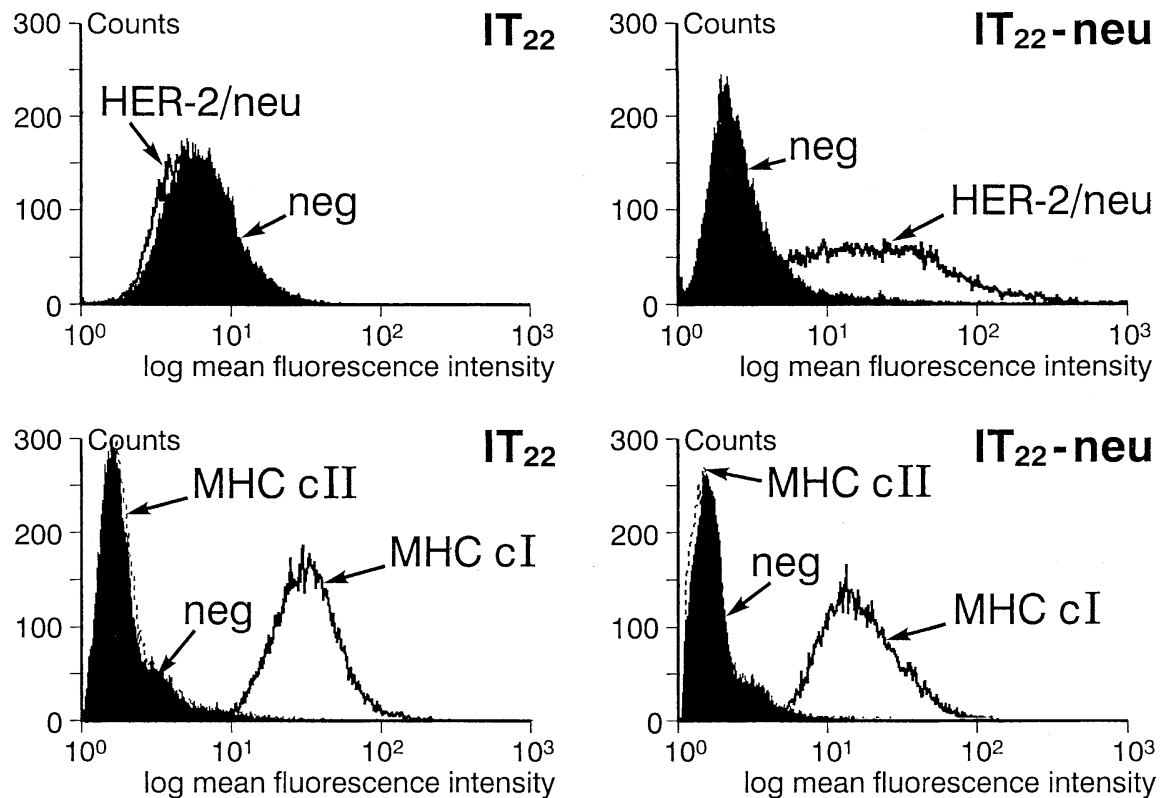
enc) would increase tumor rejection compared to free $\mathrm{p}^{\text {NeuECD }}$ injected with CFA. Female mice were vaccinated and boosted with $\mathrm{p}^{\mathrm{NeuECD}}+\mathrm{CFA}$ or the different virosomal constructs. These vaccines were tested against rVV-Neu $\mathrm{ECD}_{\mathrm{E}}$ and empty Vir as controls. Rejection of a tumor cell challenge was assessed by s.c. injection of $\mathrm{rNeu}^{+}$and $\mathrm{rNeu}^{-}$syngeneic breast cancer cells. As shown in Table 2, all mice vaccinated with empty Vir developed tumors at the injection site. They all developed their tumors within 24 days after tumor injection (range 8-24 days). Within the observation period of 8 weeks, only $27 \%$ (3 out of 11 ) of Vir-p ${ }^{\text {NeuECD }}$ mem-vaccinated mice and only $30 \%$ (3 out of 10) of Vir-p ${ }^{\text {NeuECD }}$ mem/enc-vaccinated/boosted mice had developed tumors. Mice vaccinated with either of the Vir-p ${ }^{\text {NeuECD }}$ constructs developed an impressive protection from tumor formation when compared with mice vaccinated with $\mathrm{p}^{\mathrm{NeuECD}}+\mathrm{CFA}$, where 10 mice out of 15 tested formed tumors at the injection site. Again, these protections were shown to be rNeu-specific, as mice challenged with $\mathrm{rNeu}^{-}$breast cancer cells were not protected from tumor formation.
Mice vaccinated with rVV-Neu ${ }_{E C D}$, Vir-p ${ }^{N e u E C D}$ enc, Vir-p ${ }^{\text {NeuECD}}$ mem, or Vir- $p^{\text {NeuECD }}$ mem/enc showed no significant difference in their time to tumor formation $(p<0.5$; Fig. 4a). Thus, prophylactic vaccination with $\mathrm{p}^{\text {NeuECD }}$ in virosomes (Vir- $\mathrm{p}^{\mathrm{NeuECD}} \mathrm{mem} / \mathrm{enc}$, Vir$p^{\text {NeuECD }}$ mem, Vir-p ${ }^{\text {NeuECD }}$ enc) significantly prevented the development of tumors at the injection site, in comparison to mice vaccinated with empty Vir as controls $(p<0.02$, by Mann-Whitney rank test). In contrast, free $p^{\text {NeuECD }}+$ CFA showed no significant difference in time to tumor formation compared with empty Vir $(p<1.5)$. As shown in Fig. 4a, all mice developed tumors within 26 days after tumor cell injection, independent of the vaccine used.

We further investigated the progression of tumor volume in mice with different vaccinations. As shown in Fig. $4 \mathrm{~b}$, there was no significant difference in the tumor volume 14 days after first detection of tumor formation in mice vaccinated with the different Vir-p ${ }^{\text {NeuECD }}$ constructs. The tumor progression and tumor volumes were not different between the groups either vaccinated with the different Vir-p ${ }^{\text {NeuECD, }}$, rVV-Neu $\mathrm{ECD}_{\text {(two mice }}$
Fig. 3 a rNeu-specific CTL activity in mice vaccinated with different DNA-based vaccines. Mice were vaccinated/boosted with the indicated vaccines: WT-VV i.p. (solid diamond), rVV-Neu $\mathrm{ECD}$ i.p. (solid square), fDNA s.c. (solid circle), fDNA$\mathrm{Neu}_{\mathrm{ECD}}$ s.c. (shaded open square), or Vir-DNA-Neu $\mathrm{ECD}$ i.p. (solid triangle); $2-5$ weeks after the second vaccination, spleens were removed, and CTL activity was assessed in an XTT-based assay using IT22 and IT22-neu as target cells. Similar results were seen in four independent experiments. b Humoral immune response in mice vaccinated with different DNA vectors. Mice were vaccinated and boosted with the indicated vaccines, and sera were collected 6 weeks after the first vaccination. NF9006 cells were incubated with a 1:50 dilution of serum, followed by REP-conjugated MAbs specific for mouse IgG and analyzed for fluorescence by FACScan. The mean and standard error of the mean of each group are shown
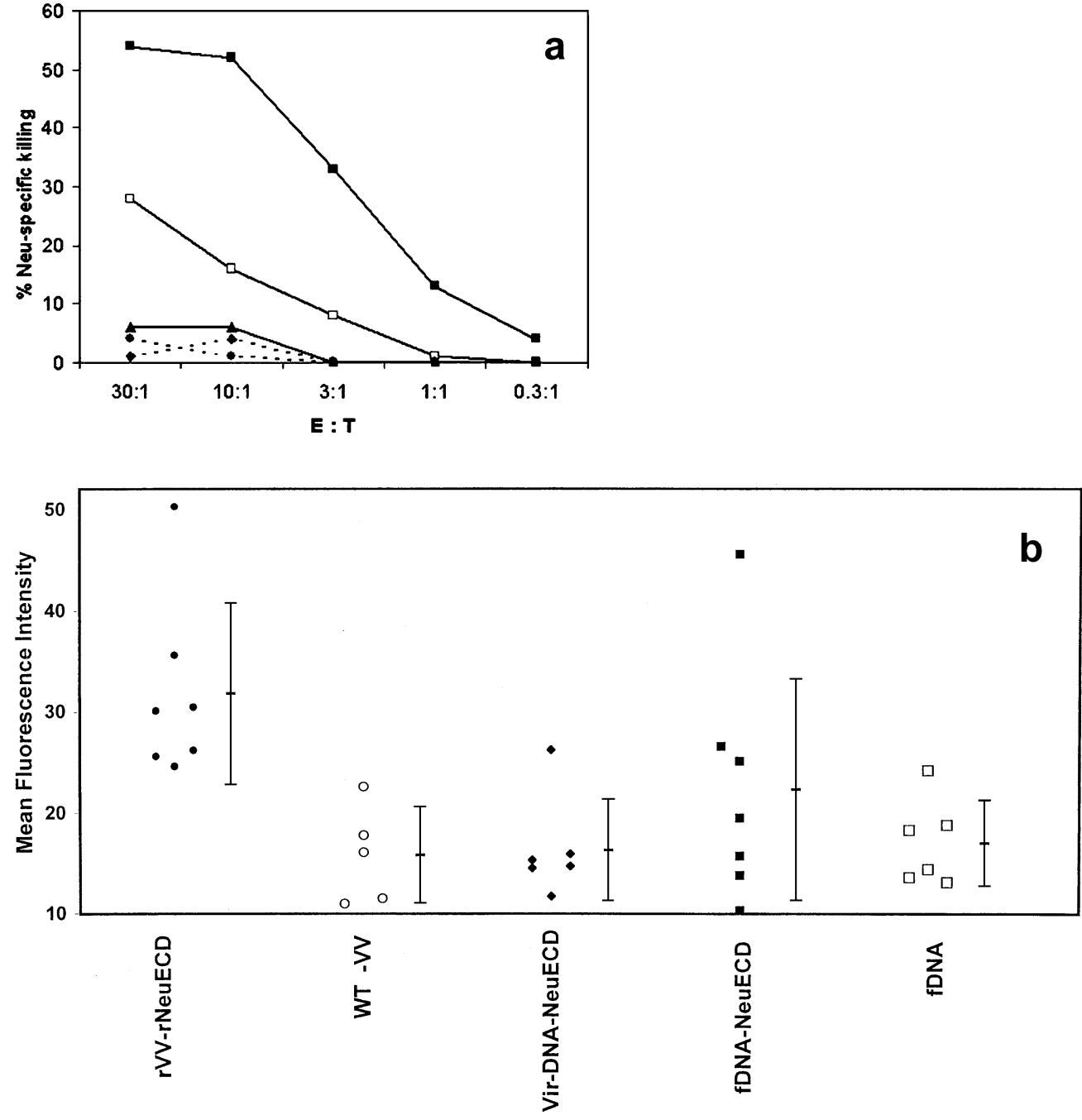
Table 2 Vaccination with virosome protein prevents tumor formation. Mice were vaccinated and boosted with rVV-Neu $\mathrm{ECD}$ i.p., $p^{\text {NeuECD }}$ enc i.p., $p^{\text {NeuECD }}$ mem i.p., $p^{\text {NeuECD }}$ enc/mem i.p., emptyVir i.p., or free $\mathrm{p}^{\mathrm{NeuECD}}$. Two weeks after the boost, each group was challenged s.c. with either $0.5 \times 10^{6} \mathrm{Neu}^{+}$tumor cells (NF9006) or $0.5 \times 10^{6} \mathrm{Neu}^{-}$tumor cells (K635), and tumor progression was monitored at the challenge site for 8 weeks. The results combine three independent experiments

Vaccination

Tumor incidence

With $\mathrm{rNeu}^{+}$challenge

With $\mathrm{rNeu}^{-}$challenge

\begin{tabular}{lllll}
\hline rVV-Neu & & $(15 \%)$ & $5 / 7$ & $(71 \%)$ \\
Vir-p $_{\text {NeuECD }}$ & $2 / 13$ & $(40 \%)$ & $5 / 5$ & $(100 \%)$ \\
Vir-p $_{\text {NeuECD }}$ mem & $4 / 10$ & $(27 \%)$ & $5 / 5$ & $(100 \%)$ \\
Vir-p $^{\text {NeuECD }}$ enc/mem & $3 / 11$ & $(30 \%)$ & $5 / 5$ & $(100 \%)$ \\
Empty Vir & $3 / 10$ & $(100 \%)$ & $3 / 3$ & $(100 \%)$ \\
Free p peuECD & $9 / 9$ & $(67 \%)$ & $5 / 5$ & $(100 \%)$ \\
\hline
\end{tabular}

Fig. 4 a Effect of prophylactic vaccination on time to tumor formation. All mice develop tumors within the same time range after tumor cell injection. $\mathrm{FvB} / \mathrm{N}$ mice were vaccinated and boosted with $\mathrm{rVV}-\mathrm{Neu} \mathrm{ECD}_{\mathrm{E}}$ i.p. (solid circle), Vir$\mathrm{p}^{\mathrm{NeuECD}}$ enc i.p. (open triangle), Vir-p ${ }^{\mathrm{NeuECD}}$ mem i.p. (open square), Vir-p ${ }^{\text {NeuECDenc/mem }}$ i.p. (open diamond), free $\mathrm{p}^{\text {NeuECD }}+$ adjuvant s.c.(solid triangle), or empty Vir i.p. (solid square). The time from tumor injection to development of palpable tumors was assessed every 3 days. Nine to 15 mice per group were compared. Statistical analysis using the Mann-Whitney rank test was performed. b The effect of the indicated vaccines on tumor progression. Tumor volume was measured every 3 days with Vernier calibers. Tumor volume was calculated using the formula $(\pi / 6) \times$ (largest diameter $) \times($ smallest diameter $)^{2}$. Shown are the combined results of three independent experiments with five mice per group. Bars represent SEM. Statistical analysis using the ANOVA rank test was performed
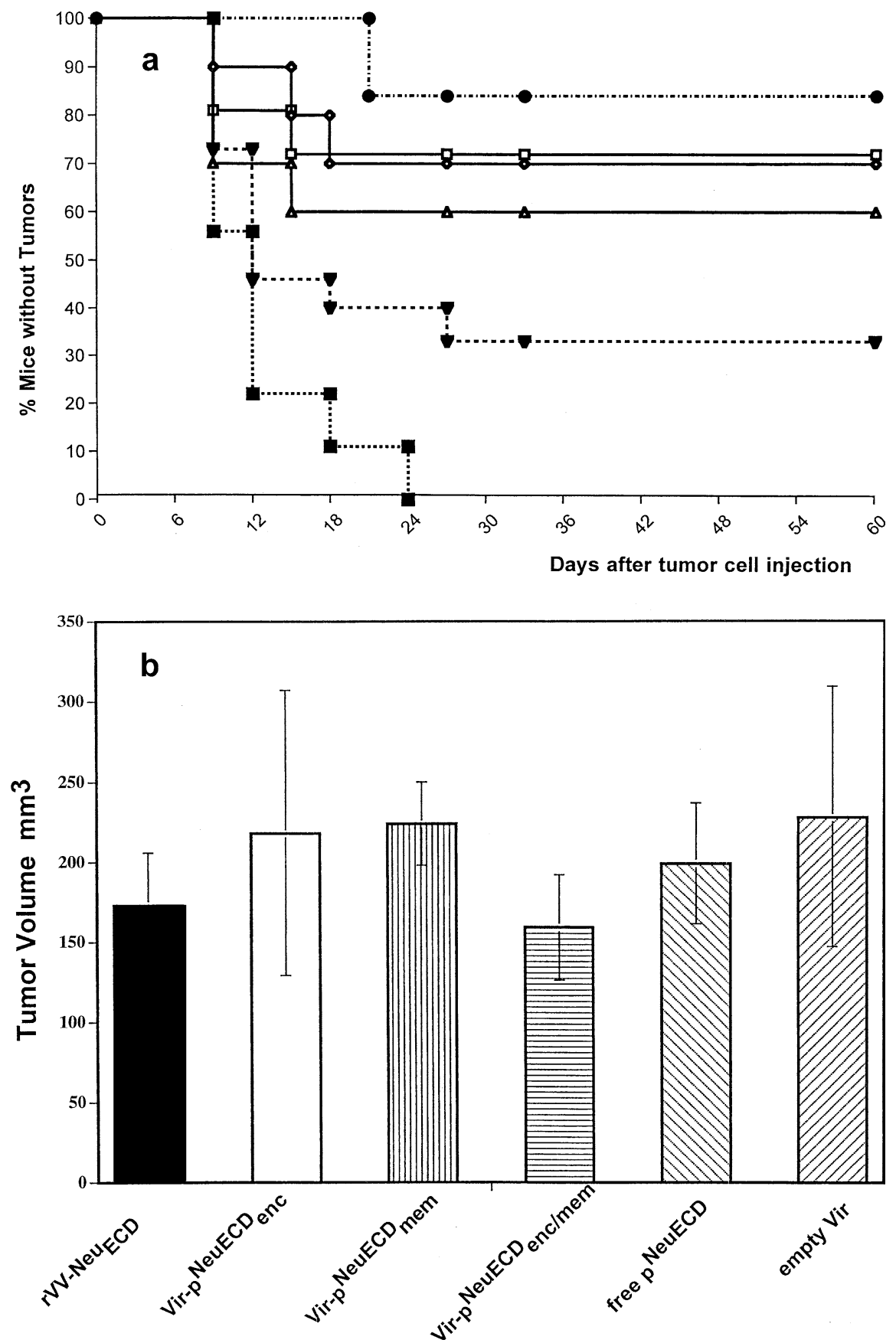
Fig. 5 a Neu-specific CTL activity in mice vaccinated with different protein-based vaccines. Mice were vaccinated/ boosted with the following vaccines: rVV-Neu $\mathrm{ECD}_{\text {i.p. }}$ (solid circle), Vir-p ${ }^{\text {NeuECD }}$ enc i.p. (open triangle), Vir-p ${ }^{N e u E C D}$ mem i.p. (open square), free $\mathrm{p}^{\mathrm{NeuECD}}+\mathrm{CFA}$ s.c.(solid triangle), or empty Vir i.p.(solid square). Two to five weeks after the second vaccination, spleens were removed, and CTL activity was assessed in an XTT-based assay using IT22 and IT22-neu as target cells. The results of one representative experiment are shown. b Humoral immune response in mice vaccinated with different protein vectors. IgG ELISA titers in sera (1:25 dilution) from mice after immunization with rVVNeuCD, different virosomal preparations containing $\mathrm{p}^{\text {NeuECD }}$, free $\mathrm{p}^{\text {NeuECD }}$, and empty virosomes. Negative control mouse sera showed $\mathrm{OD}_{450 \mathrm{~nm}}$ values between 0.07 and 0.10 . Single points represent the mean values of triplicate determinations. The mean and standard error of the mean of each group are shown

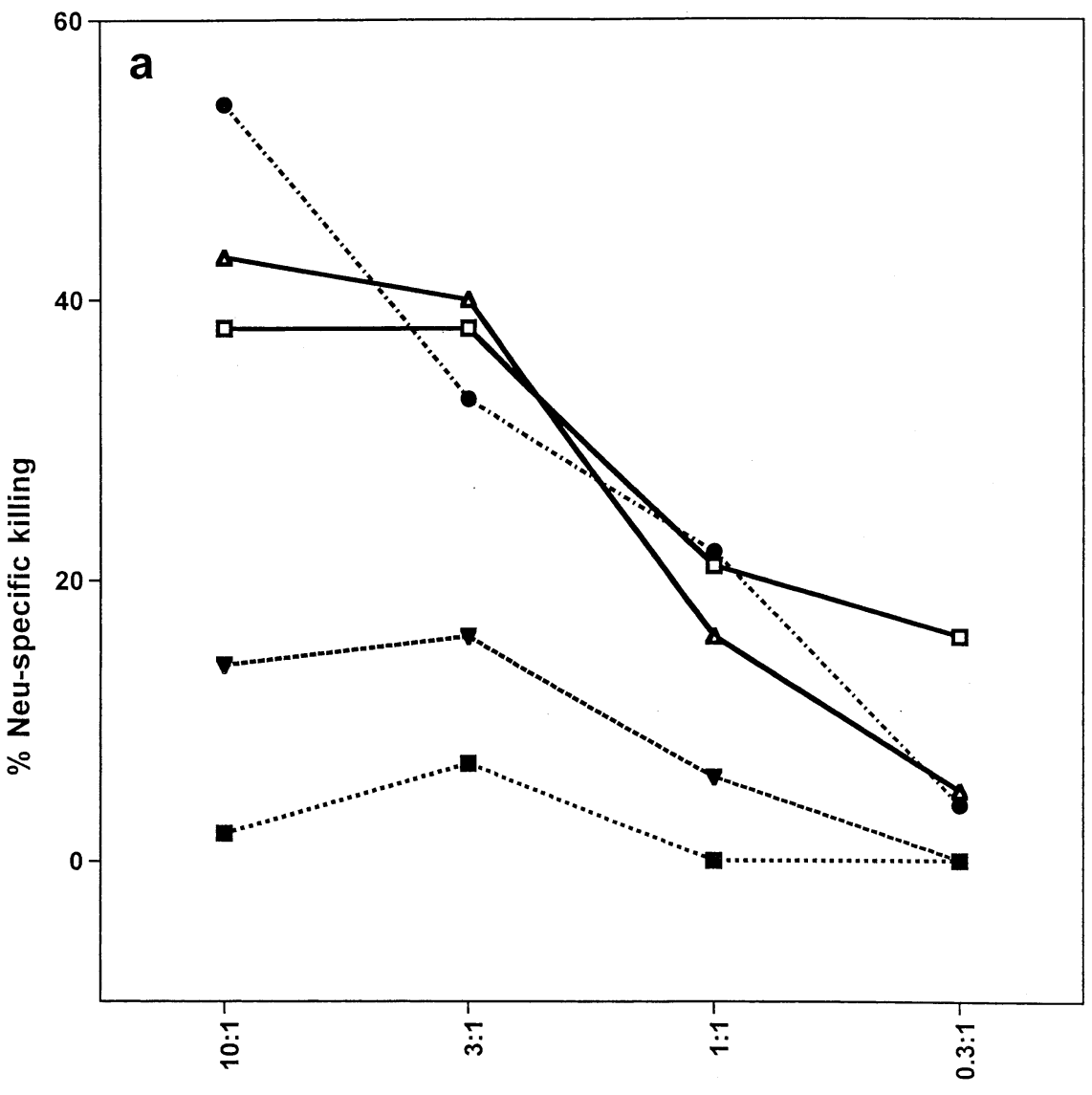

E:T ratio

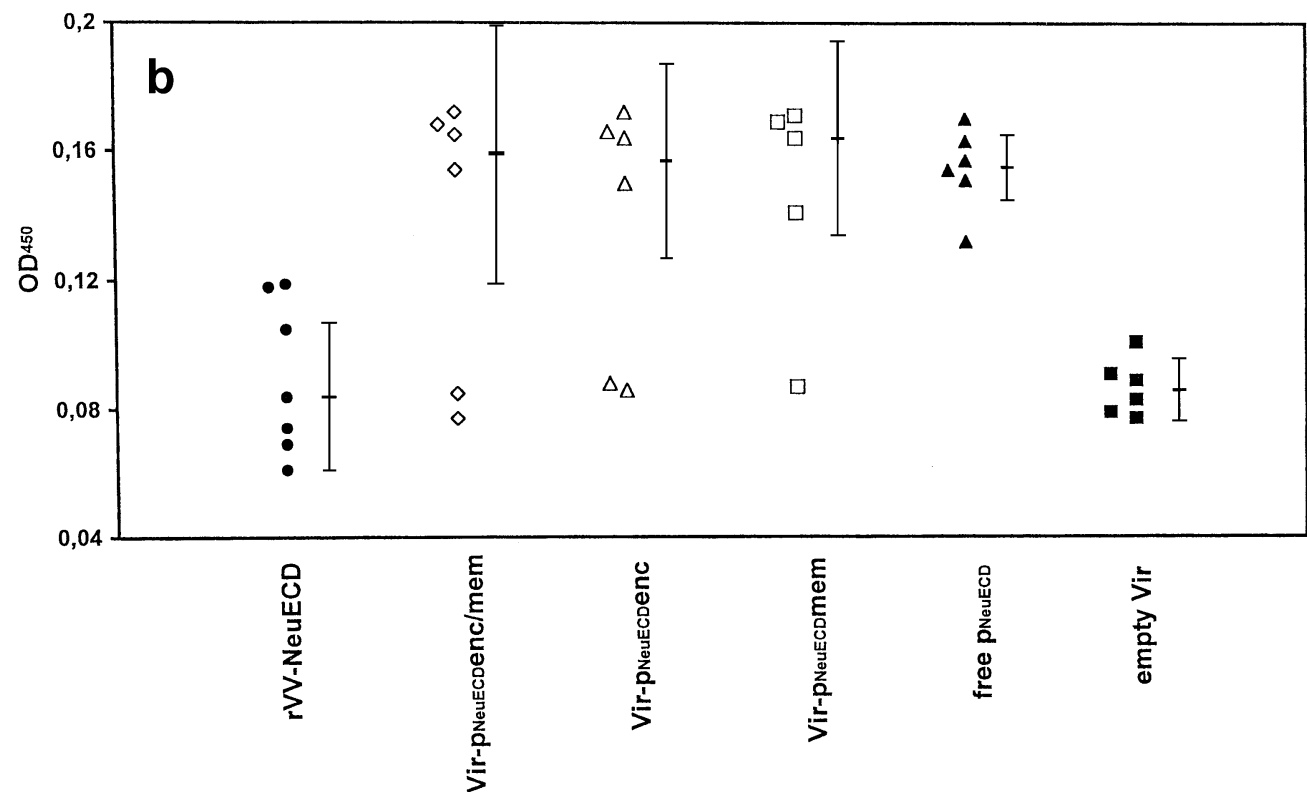

developed tumors), or empty Vir (nine mice developed tumors). These results suggest that Vir-p $\mathrm{p}^{\mathrm{NeuECD}}$ is an effective vaccine for tumor rejection; however, once the tumor has formed there was no influence on tumor progression.
Induction of both CTL and humoral immune response in Vir-p ${ }^{\text {NeuECD }}$ vaccinated mice

Previous studies have demonstrated that the immunopotentiating effect of modified reconstituted 
virosomes induced a cellular immune response [14, 25]. To demonstrate whether immunization with different Vir-p ${ }^{\text {NeuECD }}$ constructs was capable of inducing rNeuspecific CTL responses, splenocytes were isolated 7 days after booster injection and neu-specific cytotoxic activity was investigated against IT22-neu/IT22 cells. The data depicted in Fig. 5a indicated that mice immunized with Vir- $p^{\text {NeuECD }}$ enc or Vir- $p^{\text {NeuECD }}$ mem developed equally effective rNeu-specific killing in vitro at different effector to target ratios. Importantly, there was no difference in the CTL activity from that of mice vaccinated with $\mathrm{rVV}-\mathrm{Neu}_{\mathrm{ECD}}$. In contrast, mice immunized with empty Vir showed only background levels of specific cell lysis. Consistent with the lack of tumor rejection, animals vaccinated with free $p^{\text {NeuECD }}$ + CFA showed significantly lower CTL activity.

To examine whether $p^{\text {NeuECD }}$, either in the membrane or encapsulated in virosomes, could also induce anti-rNeu Abs, sera of vaccinated and boosted mice were collected 49-56 days after the first vaccination. The presence of anti-rNeu Abs was assessed by flow cytometry [23]. Whereas high levels of rNeu-specific antibodies were detected in sera from mice injected with $\mathrm{rVV}-\mathrm{Neu}_{\mathrm{ECD}}$, no rNeu-specific IgG was detected in sera of Vir-p $p^{\text {NeuECD }}$ primed mice. Since $p^{\text {NeuECD }}$ was expressed and produced in E. coli and therefore unglycosylated, the induced Abs may only recognize the protein backbone. Thus, we developed an ELISA using the same unglycosylated $\mathrm{p}^{\mathrm{NeuECD}}$ coated to plates as was used in the virosomal vaccine constructs. AntirNeu Abs were now detected in sera of animals immunized with Vir-p ${ }^{\text {NeuECD }}$ enc, Vir- $p^{\text {NeuECD }}$ mem, or a combination of both and free $\mathrm{p}^{\mathrm{NeuECD}}$. In contrast, animals vaccinated with $\mathrm{rVV}-\mathrm{Neu} \mathrm{u}_{\mathrm{ECD}}$ did not develop Abs recognizing the unglycosylated form of $p^{\text {NeuECD }}$ in this ELISA. Empty virosomes did not show a rNeuspecific humoral response in either of both systems. Taken together we showed that immunization with Vir$\mathrm{p}^{\text {NeuECD }}$ constructs induced a $\mathrm{p}^{\text {NeuECD }}$-specific cytotoxic and humoral immune response that correlated with tumor rejection.

\section{Discussion}

HER-2/neu is an antigen currently being evaluated as a target for antitumor immunotherapy. Although HER-2/ neu is constitutively expressed at low levels on different normal adult tissues, humoral and cellular immunity have been shown in patients with HER-2/neu overexpressing tumors $[5,6]$. Whereas this immunity is clearly not sufficient to provide patients with protection against malignant tumors, priming or boosting a preexisting immunity may have therapeutic effects [26, 27]. The development of new vaccines targeting HER-2/neu and designed to generate an immune response capable of rejecting cancer is still needed.

The delivery of the full-length HER-2/neu oncogene as a vaccine raises significant safety issues in patient treatment. The cytoplasmic domain of HER-2/neu exhibits a high constitutive tyrosine kinase activity, and overexpression of this oncogene on cells expressing other members of the epidermal growth factor receptor family could trigger the malignant transformation of infected cells [28]. In some cancer patients humoral and/or cellular immune responses against the extracellular part of HER-2/neu have been detected [29]. The relevance of the extracellular domain of HER-2/neu as immunogen was tested in strategies using DNA vaccines [30-32]. Repeated intramuscular injection of plasmid DNA encoding $\mathrm{rNeu}_{\mathrm{ECD}}$ provided intermediate levels of protection against a challenge with tumor cells in mice. Although complete protection was not observed with plasmid DNA, no striking difference in tumor rejection was obtained when plasmid vectors encoding the full-length rNeu protein $(\mathrm{Neu})$, the $\mathrm{rNeu}$ extracellular and transmembrane $\left(\mathrm{Neu}_{\mathrm{TM}}\right)$ domain, or the rNeu extracellular $\left(\mathrm{Neu}_{\mathrm{ECD}}\right)$ domain were used [30]. Our results supported these reports, showing that DNA-Neu $\mathrm{ECD}_{\mathrm{E}}$ could be used as vaccine and induce an effective tumor rejection combined with a humoral and cytotoxic immune response in a preclinical mouse model.

To improve the immune response and direct fDNA$\mathrm{Neu}_{\text {ECD }}$ to the cytoplasma of APCs, we used virosomes as carrier system. Virosomes are reconstituted from influenza virus envelopes and use the same cell receptormediated endocytosis as its viral counterpart [10]. The receptor binding and the membrane fusion activity of influenza virus with endosomes are known to be mediated by the major viral envelope glycoprotein HA [11, 33]. Similar to viral vectors the mildly acidic $\mathrm{pH}$ in the lumen of endosomes triggers the fusion of virosomal with endosomal membranes and thus the release of encapsulated material such as DNA, RNA, or proteins into the cytosol of APCs. Therefore, exogenous in virosomes encapsulated antigens may access the MHC class I pathway without the need of de novo protein synthesis $[11,12,14,34]$. Not all virosomes are likely to fuse with endosomal membranes, and therefore a fraction will become available for the MHC class II pathway. In the current study, we showed that DNA with virosomes as carrier system penetrated cells and induced protein expression in vitro. In contrast to previous reports, where intranasal DNA vaccines associated with virosomes were applied and induced a humoral and CTL response, Vir-DNA-Neu $\mathrm{ECD}_{\mathrm{E}}$ in our model showed neither CTL nor humoral immune responses or tumor rejection $[14,34]$. Whether the difference between these reports and our present study was only based on methods of application of the vaccine, on different vaccination strategy (priming by influenza virus), or on a different virosomal carrier system using Escheriagen (E. coli heat-labile toxin) as adjuvant is still an open question. Whereas in vitro $20-30 \%$ of the cells transfected with Vir-DNA-Neu $\mathrm{ECD}_{\mathrm{E}}$ expressed the protein, vaccination with Vir-DNA-Neu $\mathrm{ECD}_{\mathrm{E}}$ in vivo failed to induce an immune response and tumor rejection, in 
contrast to what was observed after administration of fDNA-Neu $\mathrm{ECD}_{\text {. }}$

In humans, immunization strategies using peptides or peptide-pulsed dendritic cells have been shown to be effective at priming naive $T$ cells against these peptides and proteins derived from TAAgs; however, these strategies have yet to show clinical efficacy [35].

For HER-2/neu, several immunodominant peptides have been identified, including a CTL epitope, E75 (spanning amino acids 369-377), that led to the development of a peptide-based vaccine for clinical applications [36-38]. One of these peptides (E75) was tested in a clinical setting as vaccine and was able to break tolerance and generate an anti-HER-2/neu CTL response in patients $[39,40]$. Whereas these $T$ cells easily recognized peptide-pulsed tumor cells, they failed to recognize and lyse HER-2/neu-expressing tumor cells, raising the question whether peptide-based vaccines may induce peptide-specific but not native protein-specific immune responses. Furthermore, drawbacks of synthetic peptides vaccines are their limited application due to the restriction of HLA-A2.1 epitopes in clinical indication, and their lack of standardized methods to immunize patients.

To avoid the restriction of immunodominant epitopes, as well as to generate durable immunity with putative T-helper epitopes, vaccines using the extracellular domain of HER-2/neu protein ( $\mathrm{p}^{\mathrm{NeuECD}}$ ) were investigated. Immunization of rats with human $p^{\text {NeuECD }}$ in CFA did elicit an immune response to the rat HER-2/ neu antigen (rNeu) but did not protect against tumor formation of rNeu-expressing tumors [41]. The same lack of antitumor response was seen in mice vaccinated with human $\mathrm{p}^{\mathrm{NeuECD}}$ using montaide 720 as an immunoadjuvant [42]. Along the same lines, plasmid DNA vaccines encoding for the human extracellular domain of HER-2/neu did induce only a partial or no protection from a challenge with human HER-2-expressing tumors $[30,42]$.

Bearing all these concerns in mind, we investigated the potential of virosomes as an improved protein carrier system and immunoadjuvant in cancer vaccines. Commercially available virosomal vaccines (INFLEXAL V, EPAXAL) have been shown to be very efficacious and safe [43, 44]. The potential of virosomes as delivery system has been demonstrated for nucleic acids and peptide-based vaccines, e.g., for malaria [45]. Recent reports also concluded that synthetic peptide vaccines administrated s.c. with virosomes were able to induce a strong CTL immunity [25]. Therefore virosomes are expected to generate a strong $\mathrm{B}$-cell and $\mathrm{T}$ cell immune response [9]. In this report, we demonstrated that vaccination of mice with $\mathrm{p}^{\text {NeuECD }}+$ adjuvant showed tumor rejection in only a few animals and almost no CTL activity, even when tested at different concentrations of the protein (data not shown). The immunogenic effect of $\mathrm{p}^{\mathrm{NeuECD}}$ was significantly increased when the protein antigen was linked to virosomes, either encapsulated as a soluble protein or bound to the virosomal membrane. Our results indicated that virosomes are a highly suitable carrier system for protein antigens, but did not allow any conclusions whether there is a higher efficiency in protein linked to the virosomal membrane versus its encapsulation. However, we did not observed a complete protection from tumor formation with Vir$\mathrm{p}^{\text {NeuECD }}$. One reason could be the nature of the protein antigen. We used unglycosylated proteins produced by E. coli, that did not correspond to the TAAg presented by the tumor cells. To further improve the vaccine, one could use proteins produced by eucaryotic cells with similar posttranslation modifications. Furthermore, we did not optimize the efficacy of protective immunity by changing the injection regimen. As a last alternative, the route of immunization may further improve our virosomal vaccination. In our study we noticed the strongest tumor rejection when virosomes were injected i.p.

Taken together our results show that virosomes are a highly suitable carrier system for the delivery of proteins into the cytosol of APCs and therefore effectively stimulate a cellular and humoral immune response and tumor rejection. Furthermore, the application of truncated proteins may avoid patient-specific and HLA-restricted peptide vaccines. This model is providing important preclinical data necessary for designing human vaccination trials after primary surgical treatment, either as a primary vaccination or as a boost in combination with other vaccines in a context of an adjuvant treatment plan.

Acknowledgements We thank C. Hammer for excellent technical assistance and R. Mühlbauer for statistical help. C.D.G. is supported by the Swiss National Science Foundation 32-44482.95. This work was supported by Swiss National Science Foundation grant 31-59151.99 and Stanley Thomas Johnson Stiftung and Novartis Stiftung 99B42 to C.D.G., and Beatrice Borer Stiftung, Rolex, Switzerland, to E.W.

\section{References}

1. Kapitanovic S, Radosevic S, Kapitanovic M, Ferencic Z, Tavassoli M, Primorac D, Spaventi R (1997) The expression of p185 (HER-2/neu) correlates with the stage of disease and survival in colorectal cancer. Gastroenterology 112:1103-1113

2. Ross J, Sheehan C, Hayner-Buchan A, Ambros R, LKallakury B, Kaufman R, Fisher H, Rifkin M, Muraca P (1997) Prognostic significance of HER-2/neu gene amplification status by fkluorescence in situ hybridization of prostate cancer. Cancer 79:2162-2170

3. Slamon DJ, Clark GM, Wong SG, Levin WJ, Ullrich A, McGuire WL (1987) Human breast cancer: correlation of relapse and survival with amplification of the HER-2/neu oncogene. Science 235:177-181

4. Tsai C, Chang K, Perng R, Mitsudomi T, Chen M, Gazder A (1993) Correlation of intrinsic chemoresistance of non-smallcell lung cancer cell line with HER-2/neu gene expression bvut not with ras gene mutations. J Natl Cancer Inst 85:897-901

5. Disis M, Knutson K, Schiffman K, Rinn K, McNeel D (2000) Pre-existing immunity to the HER-2/neu oncogenic protein in 
patients with HER-2/neu overexpressing breast and ovarian cancer. Breast Cancer Res Treat 62:245-252

6. Disis M, Pupa S, Gralow J, Dittadi R, Menard S, Cheever M (1997) High-titer HER-2/neu protein-specific antibody can be detected in patients with early-stage breast cancer. J Clin Oncol 15:3363-3367

7. Moss B (1996) Genetically engineered poxvirus for recombinant gene expression, vaccination and safety. Proc Natl Acad Sci U S A 93:11341-11348

8. Zajac P, Schütz A, Oertli D, Noppen C, Schaefer C, Heberer M, Süpagnoli G, Marti W (1998) Enhanced generation of cytotoxic $\mathrm{T}$ lymphocytes using recombinant vaccinia virus expressing human tumor-associated antigens and B7 costimulatory molecules. Cancer Res 58:4567-4571

9. Daemen T, De Haan A, Arkema A, Wilschut J (1998) Liposomes and virosomes as immunoadjuvant and antigencarrier systems in vaccine formulation. Med Appl Liposomes 117-143

10. Hernandez L, Hoffmann L, Wolfsberg T, White J (1996) Virus-cell and cell-cell fusion. Annu Rev Cell Dev Biol 12:627-661

11. Bungener L, Idema J, Veer W, Huckriede A, Daemen T, Wilschut J (2002) Virosomes in vaccine development: induction of cytotoxic lymphocyte activity with virosome-encapsulated protein antigens. J Liposome Res 12:155-163

12. Daemen T, Huckenriede A, Bungener L, Wilschut J (2000) Virosomes as an antigen delivery system. J Liposome Res 10:329-338

13. Peppelenbosch M, DeSmedt M, Pynaert G, Deventer S, Grooten J (2000) Macrophages present pinocytosed exogenous antigen via MHC class I whereas antigen ingested by receptormediated endocytosis is present via MHC class II. J Immunol 165:1984-1991

14. Cusi MG, Zurbriggen R, Valassina M, Bianchi S, Durrer P, Valensin P, Donati M, Glück R (2000) Intranasal immunization with mumps virus DNA vaccine delivered by influenza virosomes elicits mucosal and systemic immunity. Virololgy 277:111-118

15. Morrison BW (1994) The genetics of breast cancer. Hematol/ Oncol Clin North Am 8:15-28

16. Bargmann CI, Hung M, Weinberg AW (1986) The neu oncogene encodes an epidermal growth factor receptor-related protein. Nature 319:226-230

17. Huang L, Connor J, Wang C (1987) pH-sensitive immunoliposomes. Methods Enzymol 149:88-90

18. Waelti ER, Glück R (1998) Delivery to cancer cells of antisense L-myc oligonucleotides incorporated in fusogenic, cationic-lipid-reconstituted influenza-virus envelopes (cationic virosomes). Int J Cancer 77:728-733

19. Skehel JJ, Schild GC (1971) The polypeptide composition of influenza-A virus. Virology 44:396-408

20. Falkner FG, Moss B (1988) Escherichia coli gpt gene provides dominant selection for vaccinia virus open reading frame expression vectors. J Virol 62:1849-1854

21. Tsung K, Yim J, Buller MWML, Norton JA (1996) Gene expression and cytopathic effect of vaccinia virus inactivated by psoralen and long-wave UV light. J Virol 70:165-171

22. Céfai D, Favre L, Buri C, Wattendorf E, Marti A, Jaggi R, Gimmi C (2000) The role of Fas ligand expression in promoting escape from immune rejection in an in vivo spontaneous tumor model. Int J Cancer 91:529-537

23. Céfai D, Morrison B, Skell A, Favre L, Balli M, Leunig M, Gimmi C (1999) Targeting HER-2/neu for active-specific immunotherapy in a mouse model of spontaneous breast cancer. Int J Cancer 83:393-400

24. Krieg AS, Yi A, Matson S, Waldschmidt TJ, Teasdale BGAR, Koretzky GA, Klinman DM (1995) CpG motifs in bacterial DNA trigger direct B-cell activation. Nature 374:546-549

25. Hunziker I, Zurbriggen R, Glueck R, Engler O, Reichen J, Dai W (2001) Perspectives: towards a peptide-based vaccine against hepatitis C virus. Mol Immunol 38:475-484
26. Bernard H, Salazar L, Schiffman K, Smorlesi A, Schmidt B, Knutson K, Disis M (2002) Vaccination against the HER-2/neu oncogenic protein. Endocr Relat Cancer 9:33-44

27. Disis M, Gooley T, Rinn K, Davis D, Piepkorn M, Cheever M (2002) Generation of T cell immunity to HER-2/neu protein after active immunization with HER-/neu peptide-based vaccines. J Clin Oncol 20:2624-2632

28. Tzahar E, Yarden Y (1998) The ErbB-2/Her2 oncogenic receptor of adenocarcinomas: from orphanhood to multiple stromal ligands. Biochim Biophys Acta 1377:M25-M37

29. Disis ML, Calenoff E, McLaughlin G, Murphy AE, Chen W, Groner B, Jeschke M, Lydon N, McGlynn E, Livingston RB, Moe R, Cheever MA (1994) Existent T-cell and antibody immunity to HER-2/neu protein in patients with breast cancer. Cancer Res 54:16-20

30. Chen Y, Hu D, Eling D, Robbins J, Kipps TJ (1998) DNA Vaccines encoding full-length or truncated neu induce protective immunity against neu-expressing mammary tumors. Cancer Res 58:1965-1971

31. Rovero S, Amici A, Di Carlo E, Bei R, Nanni P, Quaglino E, Porcedda P, Boggio K, Smorlesi A, Lollini P, Landuzzi L, Colombo M, Giovarelli M, Musiani P, Forni G (2000) DNA vaccination against rat HER-2/neu p185 more effectively inhibits carcinogenesis than transplantable carcinomas in transgenic $\mathrm{BALB} / \mathrm{c}$ mice. $\mathbf{J}$ Immunol 165:5133-5142

32. Wei W, Shi W, Galy A, Lichlyter A, Hernandez S, Groner B, Heilbrun L, Jones R (1999) Protection against mammary tumor growth by vaccination with full-length, modified human ErbB2 DNA Int J Cancer 81:748-754

33. Huckriede A, Bungener L, ter Veer W, Holtrop M, Daemen T, Palache A, Wilschut J (2003) Influenza virosomes: combining optimal presentation of hemagglutinin with immunopotentiating activity. Vaccine 21:925-931

34. Correale P, Cusi M, Sabatino MM, Pozzessere LD, Nencini C, Valensin P, Petrioli R, Giorgi G, Zurbriggen R, Gluck R, Francini G (2001) Tumor-associated antigen-specific cytotoxic $\mathrm{T}$ cell response in vitro and in a mouse model, induced by TAA-plasmids delivered by influenza virosomes. Eur J Cancer 37:2097-2103

35. Morse M, Clay $\mathrm{T}$, Colling $\mathrm{K}$, Hobeika A, Grabsteiner $\mathrm{K}$, Cheever M, Lyerly H (2003) HER2 dendritic cell vaccines. Clin Breast Cancer Suppl 4:164-172

36. Fisk B, Blevins TL, Wharton JT, Ioannides CG (1995) Identification of an immunodominant peptide of HER-2/neu protooncogene recognized by ovarian tumor-specific cytotoxic $\mathrm{T}$ lymphocyte lines. J Exp Med 181:2109-2117

37. Lustgarten J, Theobald M, Labadie C, LaFace D, Peterson P, Disis M, Cheever M (1997) Identification of HER-2/neu CTL epitopes using double transgenic mice expressing HLA-A2 and human CD8. Hum Immunol 52:109-118

38. Yoshino I, Geodegebuure PS, Peoples GE, Parikh AS, DiMaio JM, Lyerly HK, Gazdar AF, Eberlein TJ (1994) HER2/neuderived peptides are shared antigens among non-small cell lung cancer and ovarian cancer. Cancer Res 54:3387-3390

39. Disis ML, Gralow JR, Bernhard H, Hand SL, Rubin WD, Cheever MA (1996) Peptide-based, but not whole protein, vaccines elicit immunity to HER-2/neu, an oncogenic selfprotein. J Immunol 156:3115-3158

40. Zaks T, Rosenberg S (1998) Immunization with a peptide epitope (p369-377) from HER-2/neu leads to peptide-specific cytotoxic T lymphocytes that fail to recognize HER-2/neu + tumors. Cancer Res 58:4902-4908

41. Taylor P, Gerder M, Moros Z, Feldmann M (1996) Humoral and cellular responses raised against the human HER2 oncoprotein are cross-reactive with the homologous product of the neu rpoto-oncogene, but do not protect rats against B104 tumors expressing mutated neu. Cancer Immunol Immunother 42:179-184

42. Foy T, Bannink J, Sutherland R, McNeill P, Moulton G, Smith J, Cheever M, Grabstein K (2001) Vaccination with HER-2/neu DNA or protein subunits protects against growth 
of a HER-2/neu expressing murine tumor. Vaccine 19:25982606

43. Glueck R, Mischler R, Finkel B, Que J, Scarpa B, Cryz S (1994) Immunogenicity of new virosome influenza vaccine in elderly people. Lancet $344: 160-163$

44. Holzer B, Hatz C, Schmidt-Sissolak D, Glueck R, Althaus B, Egger M (1996) Immunogenicity and adverse effects of inacti- vated virosome versus alum-absorbed hepatitis A vaccine: a randomised controlled trial. Vaccine 14:982-986

45. Poeltl-Frank F, Zurbriggen R, Helga A, Stuart F, Robinson J, Glueck R (1999) Use of reconstituted influenza virus virosomes as an immunopotentiating delivery system for a peptide based vaccine. Clin Exp Immunol 117:496-503 